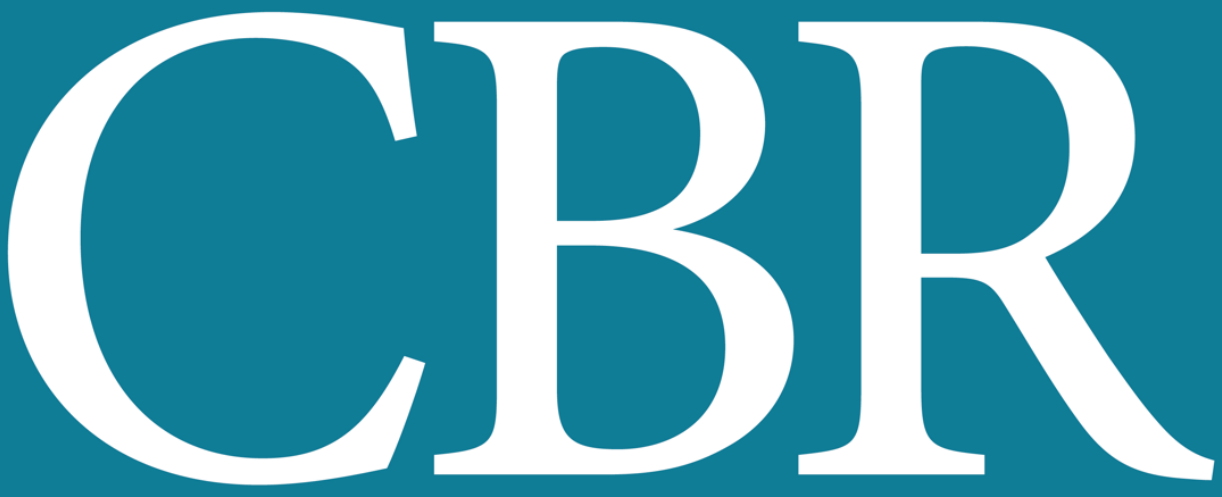

INTERNATIONAL JOURNAL OF CANCER AND BIOMEDICAL RESEARCH

https://jcbr.journals.ekb.eg

Editor-in-chief

Prof. Mohamed Labib Salem, PhD

Indications and outcomes of endoscopic ultrasound in Tanta-Egypt: Initial experience

Heba F. Harras, Ferial S. El-Kalla, Asem A. Elfert, Lobna Abo Ali, Samah M. Soliman, Walaa Elkhalawany, Yomna Zamzam, Mohamad Alnadi, Islam S. Ismail, Reham Elkhouly 


\section{Welcome letter from Editor-in-Chief}

Welcome to the Int J Cancer and Biomedical Research (IJCBR)!

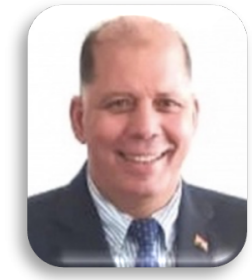

It is with great pleasure that I write this editorial to welcome you to the IJCBR. This journal provides a platform for publication of original and reviews research articles, short communications, letter to editor, thesis abstract, conference report, and case studies. These types of publication are directed at the interface of the fields of cancer and biomedical research.

The IJCBR relies on a distinguished expert of the Advisory and Editorial Board Members from the top international league covering in depth the related topics. They timely review all manuscripts and maintain highest standards of quality and scientific methodology and ethical concepts. Meanwhile, we take all possible means to keep the time of the publication process as short as possible.

I take this chance to welcome your contributions to the IJCBR and have every expectation that it will soon become one of the most respected journals in both the fields of cancer and biomedical research.

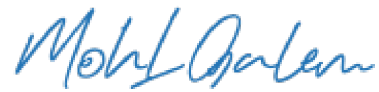

Mohamed L. Salem,

Editor in Chief 


\title{
Indications and outcomes of endoscopic ultrasound in Tanta-Egypt: Initial experience
}

\author{
Heba F. Harras ${ }^{1}$, Ferial S. El-Kalla², Asem A. Elfert ${ }^{2}$, Lobna Abo Ali², Samah M. Soliman², Walaa Elkhalawany², \\ Yomna Zamzam ${ }^{1}$, Mohamad Alnadi ${ }^{3}$, Islam S. Ismail ${ }^{2}$, Reham Elkhouly ${ }^{2}$ \\ ${ }^{1}$ Department of Pathology, Tanta University, Tanta, Egypt \\ ${ }^{2}$ Department of Tropical Medicine and Infectious Diseases, Tanta University, Tanta, Egypt \\ ${ }^{3}$ Department of Internal Medicine, Cairo University, Cairo, Egypt
}

\section{ABSTRACT}

Background: Endoscopic ultrasound (EUS) is valuable in the diagnosis and staging of gastrointestinal tumors and some extra-luminal malignancies. Aim: This study aimed to describe the initial experience with EUS and fine-needle aspiration (FNA) and the indications and outcomes of patients at the Tanta University Teaching Hospital. Subjects and Methods: This is a cross-sectional descriptive survey study analyzing 70 EUS cases seen at Tanta University Teaching Hospital from January to December 2019. FNA was performed for 61 patients. A provisional cytopathology diagnosis was made by on-site and the final cytology/histopathology report was given after immunostaining and review of slides. Results: The major indications for EUS were pancreatic, gastric, and ampulla of Vater lesions. EUS revealed pancreatic masses in 27, cysts in 1, and chronic pancreatitis in 1 case. Gastric masses were seen in 13, polyps in 5, and varices in 3 cases. Ampulla of Vater lesions were masses in 5, common bile duct (CBD) distal end stones in 3 cases, and one case proved normal. The final diagnosis of pancreatic lesions was adenocarcinoma in 25, cyst in 1 case, mucoepidermoid tumour in 1 case, neuroendocrine tumour in 1 case and chronic pancreatitis in 1 case. Gastric lesions were gastrointestinal stromal tumors (GIST) in 8 , and adenocarcinoma in 5 cases, while 3 cases of polyps were hyperplastic, one inflammatory and one tubulovillous adenomatosis. Celiac axis block was done for 6 cases. No major complications were recorded. Conclusion: The major indications for EUS were pancreatic, gastric and ampulla of Vater lesions, while the main outcomes were pancreatic adenocarcinoma, gastric GIST, adenocarcinoma and ampullary adenocarcinoma.

Keywords: Celiac axis block, Cytopathology, Endoscopic ultrasound, Fine needle aspiration, Pancreatic lesions

Editor-in-Chief: Prof. M.L. Salem, Ph.D. - Article DOI: 10.21608/JCBR.2020.35939.1058

\section{ARTICLE INFO}

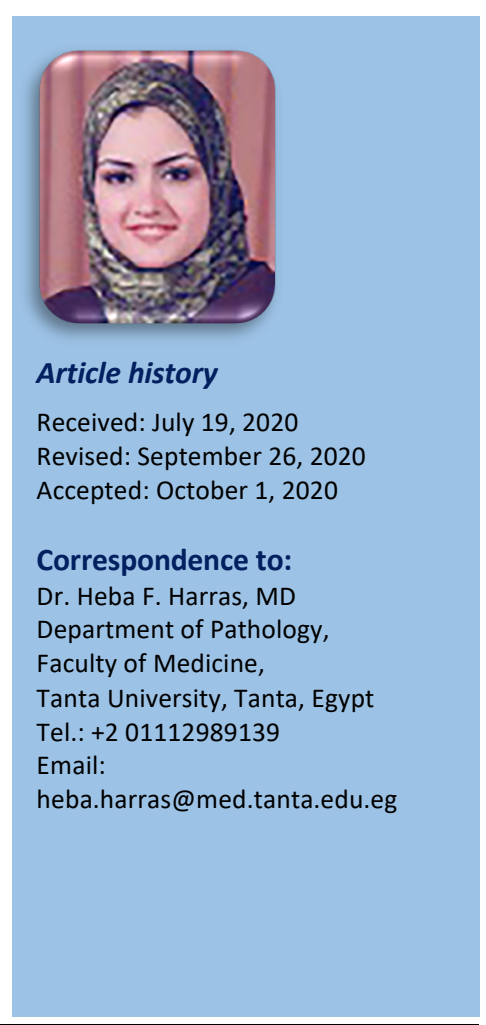

\section{INTRODUCTION}

Endoscopic ultrasound (EUS) is characterized by high resolution which presents perfect and exceedingly meticulous images of the gastrointestinal (GI) wall and nearby structures up to $4-5 \mathrm{~cm}$ (Strohm et al., 1980, Bhutani, 2000). It has many indications but is mostly used to detect and stage $\mathrm{Gl}$ lesions originating from deep layers, as well as some extra-luminal masses, including pancreatic cancers (Brugge 1998, Byrne and Jowell 2002). EUS has been highly used to determine the nature, detect the layer of origin and allow for sampling of bulging gastric lesions determined by conventional endoscopy specially when arising from below the mucosa (Strohm et al., 1980, Byrne and Jowell, 2002).

Other indications of EUS include chronic pancreatitis, pancreatic lesions in the form of masses or cysts, and gall bladder masses (Brugge, 1998; Bhutani, 2000). Evaluation of lesions outside the gastrointestinal tract (GIT), such as mediastinal lymph nodes enlargement of unknown cause is an indication of EUS (Byrne and Jowell 2002). Another advantage of EUS is the estimation of the degree of fibrosis through detection of tissue stiffness by EUS tissue elastic 
imaging (Deprez, 2013, Saftoiu and Vilmann, 2013).

EUS-guided fine needle aspiration (FNA) biopsy is a meticulous, safe procedure used to differentiate between benign and malignant lesions; determine tumor stage and apply histological confirmation of malignancy needed to select the best line of treatment including; chemotherapy, radiotherapy, or even surgery (Hawes, 2010; Dumonceau et al., 2011).

The present study was conducted to determine common indications for requesting EUS and to describe the diagnoses made after endoscopic ultrasound/fine-needle aspiration and cytology (FNAC), the indicated therapeutic procedures and prognosis for cases seen at the Tanta University Teaching Hospital in 2019.

\section{SUBJECTS AND METHODS}

This is a cross-sectional descriptive survey study of the initial EUS experience at the Tanta University teaching hospital during the period from January 2019 to December 2019. Institutional ethical committee approval was obtained before the start of the study and informed consent was signed by every patient before enrolment. The study was registered on clinicaltrials.gov (ClinicalTrials.gov Identifier: NCT03267355).

All patients referred for EUS were screened for study participation. The patients were referred for one of the following indications: (1) detailed imaging and FNA of mediastinal, gastric, ampullary, or pancreatic lesions (2) staging of previously diagnosed gastric and pancreatic cancers for TNM classification. Patients too ill (hypoxemic/ hypotensive) to undergo the procedure safely or having unacceptable sedation risks and those with large upper esophageal tumors preventing the advancement of the scope/EUS probe were excluded.

A detailed history was taken from every patient, previous investigations (upper GIT endoscopy, chest or abdominal CT) were reviewed and the procedure was explained to the patients. Indications were documented as per the site of pathology, including lymph node, pancreas, stomach, ampulla of Vater, esophagus, and mediastinum. A comprehensive clinical and laboratory pre-procedure assessment including PT and INR was performed for each patient. Patients were instructed not to ingest any food or drink for 8 hours before the procedure.

An experienced endosonographer aware of the patients' clinical history performed the procedure using a Pentax EG-3870UTK with a Hitachi system EUS linear scope. Patients were given conscious sedation using midazolam/nalophen. EUS findings were recorded against indications as enlarged lymph nodes, tumor staging or normal.

TNM classification was used for staging of esophageal, gastric, ampullary and pancreatic tumors which were detected by EUS (Amin et al. 2017). Fine-needle aspiration cytology (FNAC) was performed as determined by the EUS findings using 22 gauge needles (ECHO 3-22 Cook Medical Echotip Ultra with HDFNA G 3152122 ga USA), five to fifteen passes were performed by moving the needle back and forth within the target using the fanning or the capillary technique as needed.

\section{Smearing technique}

Immediately after the FNA specimens were obtained, two to four smears were prepared using positively charged slides, fixed immediately in $95 \%$ ethanol and stained with Haemotoxylin and Eosin (H\&E). Any excessive material, including the needles used in aspiration, was submitted in 50\% ethanol (ethanol/water, 1:1) for cell block preparation (Skipper and DeStephano, 1989).

A histopathologist attended each procedure and air-dried slides were reviewed for adequacy of tissue and provisional cytopathological diagnoses were made. The obtained cytological diagnoses were classified into benign and malignant.

\section{Cell blocking}

After preparation of the smears, the syringes and needles used for the fine-needle aspirates were rinsed in $10 \mathrm{ml}$ of $50 \%$ ethanol in a container. Any residual tissues or clots in the hub of needles used for aspiration were removed meticulously in the laboratory with the help of another needle and rinsed in 50\% ethanol. The whole specimen was centrifuged in 
a $10 \mathrm{ml}$ disposable centrifuge tube at 4,000 rpm for 6 minutes to create a single pellet (Hecht $S$ 2013).

Nathan alcohol formalin substitute (NAFS) consisting of 9 parts of $100 \%$ ethanol and 1 part of $40 \%$ formaldehyde was prepared freshly then the deposit was fixed in it. After 45 minutes of fixation, re-centrifugation was done for 6 minutes. These pellets detached themselves or were removed easily with a disposable Pasteur pipette following centrifugation. The cell pellets were covered with crayon paper, placed in a cassette, and kept in $80 \%$ ethanol until ready for processing in the automatic tissue processor. The cell blocks were embedded in paraffin and sectioned at $4 \mu \mathrm{m}$ thickness (Hecht, 2013 ).

\section{Staining}

Routine H\&E staining was performed for all cell block sections. According to the manufacturer's instructions for the kits, Immunohistochemical staining using LCA monoclonal mouse antihuman antibody clone 2B11 + PD7/26 (Code no. M0701, Dako), polyclonal rabbit anti-human Ckit (code no. A4502, Dako), Monoclonal rabbit chromogranin A antibody (SP12)(code no. MA514536, Thermofisher scientific) or monoclonal mouse cytokeratin 7 antibody clone OV-TL 12/30 (code no.MA1-06316, Thermofisher Scientific) for identification or phenotyping of tumor cells using the streptavidin-biotin method was done after the provisional cytopathological diagnosis. Further investigations and work-up like ERCP with stenting, surgical and/ or oncology consultation were done when desired. Therapeutic procedures were performed when indicated, including coeliac axis block and aspiration of a pancreatic cyst.

EUS guided coeliac axis block was done by FNA needle which was prepared by flushing the device with $0.9 \%$ saline solution. After removal of the stylet, a syringe with $5 \mathrm{ml}$ of saline solution was attached to the hub of the needle. The needle assembly was passed through the biopsy channel and advanced under direct EUS visualization to a position immediately alongside and anterior to the aorta. Aspiration was performed, and if no blood was seen, $4 \mathrm{cc}$ Bupevacain, $2 \mathrm{cc}$ Triamcinolone and $20 \mathrm{cc}$ of absolute alcohol were injected at the base of the celiac trunk (central injection).

Pancreatic cyst EUS guided aspiration was performed by the FNA needle while the endoscope tip was positioned in the duodenum. The needle was inserted into the center of the cyst, the stylet withdrawn, and the vacuum applied. The fluid was aspirated and the cyst thoroughly emptied, after which a sample was taken from the cyst wall for cytopathological analysis.

\section{Statistical analysis}

The statistical data are reported as the mean \pm standard deviation (SD), frequencies (number), and percentages when appropriate. Percentages and frequencies were determined for various variables (indications, diagnosis, and treatment modalities). All statistical analyses were performed using the computer program SPSS (Statistical Package for the Social Science; SPSS, Chicago, Illinois, USA) version15 for Microsoft Windows.

\section{RESULTS}

In total, 81 patients were screened for study participation and 11 were excluded. Of those excluded, 8 had failures in exclusion criteria, and 3 declined to participate. Thus, seventy patients underwent EUS during the study period; 45 (64.3\%) were males and 25(35.7\%) females. Age ranged from 32 to 69 years with a mean of $50.87 \pm 9.87$ years. The mean procedure time was $37 \pm 10.2$ minutes (range $22-65 \mathrm{~min}$ ).

The indications for patients' referral for EUS are shown in Table 1. The most frequent indication of EUS in this study was abnormal pancreatic imaging (mass lesion, fullness or prominence of the pancreatic head on ultrasound or CT abdomen) in $41.43 \%$ of cases. Gastric lesions were the second major indication in $30 \%$ of the cases followed by ampullary lesions in $12.85 \%$ cases.

EUS findings of the patients are shown in Table 2. The pancreatic lesions were masses in 27 , cyst in 1 , and chronic pancreatitis in 1 patient (Fig. $1)$. Gastric lesions were masses in 13 , polyps in 5 , and varices in 3 patients. Ampullary lesions were found to be masses in 5 , stones of the distal common bile duct (CBD)in 3 , and one 
patient referred for a suspected enlargement of the ampulla of Vater was proved to be normal by EUS (Figure 2).

FNAC was performed for 61 patients out of 70 . The nine patients for whom FNAC was not done were; 3 with gastric varices, 3 with CBD stones, and 3 with normal EUS findings for whom the clinically suspected pathology was not found (one patient with suspected enlargement of the ampulla of Vater and 2 patients with abdominal pain who were diagnosed with irritable bowel syndrome (IBS).

Table 1. Indications for EUS

\begin{tabular}{lcc}
\hline Indication & No & \% \\
\hline Pancreas & 29 & 41.43 \\
Stomach & 21 & 30.00 \\
Ampullary lesions & 9 & 12.86 \\
Mediastinum & 3 & 4.28 \\
Esophagus & 2 & 2.86 \\
Miscellaneous: & & \\
Left suprarenal mass & 1 & 1.43 \\
Splenic focal lesion & 1 & 1.43 \\
Abdominal lymphadenopathy & 2 & 2.86 \\
Abdominal pain & 2 & 2.86 \\
Total & $\mathbf{7 0}$ & $\mathbf{1 0 0}$ \\
\hline
\end{tabular}

FNAC/cytopathology diagnosis of the lesions is shown in Table 3. Pancreatic lesions were adenocarcinoma in 23 patients, and one patient of each of the following: simple cyst, mucoepidermoid tumour, neuroendocrine tumour, and chronic pancreatitis (Figure 3). As regards the TNM classification of pancreatic adenocarcinoma; $\mathrm{T}$ stage was from $\mathrm{T} 1$ to $\mathrm{T} 4$ and $\mathrm{N}$ and $\mathrm{M}$ stages of most cases were $\mathrm{NO}$ and $\mathrm{MO}$.

Of the 13 gastric masses, 8 proved to be gastrointestinal stromal tumors (GIST) (Fig. 4), and 5 adenocarcinomas, the other gastric lesions detected were polyps; hyperplastic in 3, inflammatory in 1, and tubulovillous adenomatosis in 1 patient. The staging of the 8 GIST tumors revealed: 2 high risk (T2N1M1 and T2NOMO) and 6 low risk (T1NOMO). All five gastric adenocarcinoma patients were found to be of stage (T3N1M1).

The five ampullary masses proved to be periampullary adenocarcinoma. Out of the 3 mediastinal masses, there was one lymphoma (Figure 5), one anaplastic carcinoma and a case of sarcoidosis. Treatment modalities of the patients are shown in Table 4. Treatment was indicated for 69 patients out of 70, as the case with suspected enlargement of the ampulla of Vater which proved normal by EUS needed no treatment apart from patient reassurance.

EUS-guided therapeutic interventions were few. EUS guided coeliac axis block was done to treat abdominal pain associated with pancreatic cancer in 5 patients and chronic pancreatitis in one case. Also, EUS guided complete aspiration of a pancreatic cyst located in the head of the pancreas was successfully done for one patient and complete resolution of the cyst was achieved. There were no major complications recorded by this study. Minor intraluminal bleeding after FNAC was reported in two (3\%) patients out of 61, and transient hypotension after EUS guided coeliac axis block in one (16.6 $\%)$ out of 6 .

\section{DISCUSSION}

EUS is used to get images of lesions originating from any layer of the GIT and also from all around organs to a depth of about 5 centimeters (Bhutani, 2000). Pancreatico-biliary and mediastinal lesions are important indications of EUS too. FNA guided by EUS is needed to differentiate between benign and malignant lesions and to estimate the malignant lesions' stage before surgical intervention, chemotherapy or radiotherapy(Strohm et al., 1980; Brugge, 1998; Byrne and Jowell, 2002).

The main indication of EUS in this study was the assessment of pancreatic lesions (41.42\%) with pancreatic adenocarcinoma being the major underlying etiology (35.71\%). This is similar to another study in USA, in which EUS was performed for 7614 cases and the authors concluded that evaluation of the pancreas accounts for approximately $40 \%$ of the indications for EUS (D'Souza et al., 2016). On the other hand, another study reported that pancreatico-biliary lesions (29.6\%) were the second indication for EUS after esophageal lesions (30.7\%) in a study including 526 Australian patients (Kalade et al., 2006).

The most valuable execution of EUS in hepatobiliary disease is to visualize and stage pancreatic and distal biliary neoplasms and to perform the same session EUS ultrasound- 
guided fine-needle aspiration in the same session for cytologic diagnosis(Hussain et al. 2009). EUS/FNA is minimally invasive and very definitive in getting tissue samples for the diagnosis of solid pancreatic tumors. EUS is indispensable in guiding biopsy needles into lesions that cannot be identified by $\mathrm{CT} / \mathrm{MRI}$ because of its small size or surrounded by high vascularity which makes safe percutaneous biopsy impossible (Hewitt et al., 2012). The second most common indication for EUS in our study was the assessment of gastric lesions, accounting for (30\%) of all the EUS cases carried out.

Table 2. EUS findings

\begin{tabular}{llcc}
\hline \multirow{2}{*}{ Indication } & EUS findings & No & $\%$ \\
\hline Pancreas & Mass & 27 & 38.57 \\
$(\mathrm{n}=29)$ & Cyst & 1 & 1.43 \\
& Chronic pancreatitis & 1 & 1.43 \\
\hline Stomach & Mass & 13 & 18.57 \\
$(\mathrm{n}=21)$ & Polyps & 5 & 7.14 \\
& Varices & 3 & 4.28 \\
\hline Ampullary lesions & Mass & 5 & 7.14 \\
$(\mathrm{n}=9)$ & Common bile duct stones & 3 & 4.28 \\
& Normal & 1 & 1.43 \\
\hline \multirow{2}{*}{ Mediastinum ( $\mathrm{n}=3)$} & Mass & 3 & 4.28 \\
\hline \multirow{2}{*}{ Esophagus( $\mathrm{n}=2)$} & Mass & 2 & 2.86 \\
\hline Miscellaneous $(\mathrm{n}=6)$ & Left suprarenal mass & 1 & 1.43 \\
& Splenic focal lesion & 1 & 1.43 \\
& Abdominal lymphadenopathy & 2 & 2.86 \\
& Normal & 2 & 2.86 \\
\hline Total & & 70 & 100 \\
\hline
\end{tabular}

Table 3. Final diagnosis on fine-needle aspiration and cytology/cytopathology

\begin{tabular}{|c|c|c|c|}
\hline FNAC & Diagnosis & No & $\%$ \\
\hline \multirow[t]{5}{*}{ Pancreas $(n=29)$} & Pancreatic adenocarcinoma & 25 & 35.71 \\
\hline & Cyst & 1 & 1.43 \\
\hline & Mucoepidermoidtumour & 1 & 1.43 \\
\hline & Neuroendocrine tumour & 1 & 1.43 \\
\hline & Chronic pancreatitis & 1 & 1.43 \\
\hline \multirow[t]{5}{*}{ Stomach $(n=18)$} & GIST & 8 & 11.43 \\
\hline & Adenocarcinoma & 5 & 7.14 \\
\hline & Hyperplastic polyps & 3 & 4.28 \\
\hline & Inflammatory polyp & 1 & 1.43 \\
\hline & Tubullovillous adenomatous polyps & 1 & 1.43 \\
\hline Ampullary lesions $(n=5)$ & Adenocarcinoma & 5 & 7.14 \\
\hline \multirow[t]{3}{*}{ Mediastinum $(n=3)$} & Lymphoma & 1 & 1.43 \\
\hline & Anaplastic carcinoma & 1 & 1.43 \\
\hline & Sarcoidosis & 1 & 1.43 \\
\hline Esophagus(n=2) & Leiomyoma & 2 & 2.86 \\
\hline \multirow[t]{2}{*}{ Miscellaneous ( $n=4)$} & Lymphoma & 3 & 4.28 \\
\hline & Lt. suprarenal adenocarcinoma & 1 & 1.43 \\
\hline FNAC/Cytopathology & Gastric varices & 3 & 4.28 \\
\hline not done/indicated & Common bile duct stone & 3 & 4.28 \\
\hline$(n=9)$ & Normal EUS findings & 3 & 4.28 \\
\hline Total & & 70 & 100 \\
\hline
\end{tabular}

EUS: endoscopic ultrasound; GIST: gastrointestinal stromal tumour. 
Table 4. Patient treatment modalities

\begin{tabular}{|c|c|c|}
\hline Treatment modality & No & $\%$ \\
\hline \multicolumn{3}{|l|}{$\operatorname{ERCP}(n=21)$} \\
\hline Palliative stent insertion for pancreatic adenocarcinoma & 15 & 21.42 \\
\hline Palliative stent insertion for ampullary adenocarcinoma & 3 & 4.28 \\
\hline Stone removal from the distal end of CBD & 3 & 4.28 \\
\hline \multicolumn{3}{|l|}{ Surgical management $(n=19)$} \\
\hline Gastric GIST excision & 7 & 10.00 \\
\hline Esophageal leiomyomas & 2 & 2.86 \\
\hline Ampullectomy (ampullary adenocarcinoma) & 2 & 2.86 \\
\hline Pancreatic adenocarcinoma excision & 2 & 2.86 \\
\hline Whipple's operation & 1 & 1.43 \\
\hline Gastric Tubullovillous adenomatous polyp excision & 1 & 1.43 \\
\hline Gastric adenocarcinoma excision & 1 & 1.43 \\
\hline Pancreatic mucoepidermoid cyst excision & 1 & 1.43 \\
\hline Pancreatic neuroendocrine tumour excision & 1 & 1.43 \\
\hline Left suprarenal adenocarcinoma excision & 1 & 1.43 \\
\hline \multicolumn{3}{|l|}{ Chemotherapy $(n=12)$} \\
\hline Lymphoma & 4 & 5.71 \\
\hline Gastric adenocarcinoma & 4 & 5.71 \\
\hline Pancreatic adenocarcinoma & 2 & 2.86 \\
\hline Mediastinal metastatic lymphadenopathy (anaplastic carcinoma) & 1 & 1.43 \\
\hline Gastric GIST & 1 & 1.43 \\
\hline EUS guided coeliac axis block & & \\
\hline Pancreatic adenocarcinoma & 5 & 7.14 \\
\hline Chronic pancreatitis & 1 & 1.43 \\
\hline EUS guided aspiration of pancreatic cyst $(n=1)$ & 1 & 1.43 \\
\hline \multicolumn{3}{|l|}{ Others $(n=10)$} \\
\hline Endoscopic polypectomy & 2 & 2.86 \\
\hline Glue injection of gastric varices & 1 & 1.43 \\
\hline EMR of hyperplastic prepyloric polyp & 1 & 1.43 \\
\hline Medical treatment of IBS & 2 & 2.86 \\
\hline Medical treatment of gastric varices & 2 & 2.86 \\
\hline Medical treatment of sarcoidosis & 1 & 1.43 \\
\hline Triple therapy for H.Pylori & 1 & 1.43 \\
\hline Reassurance (n=1) & 1 & 1.43 \\
\hline Total & 70 & 100 \\
\hline
\end{tabular}

EMR: endoscopic mucosal resection; ERCP: endoscopic retrograde cholangiopancreatography; EUS: endoscopic ultrasound; CBD: common bile duct; GIST: gastrointestinal stromal tumour; IBS: irritable bowel syndrome. 

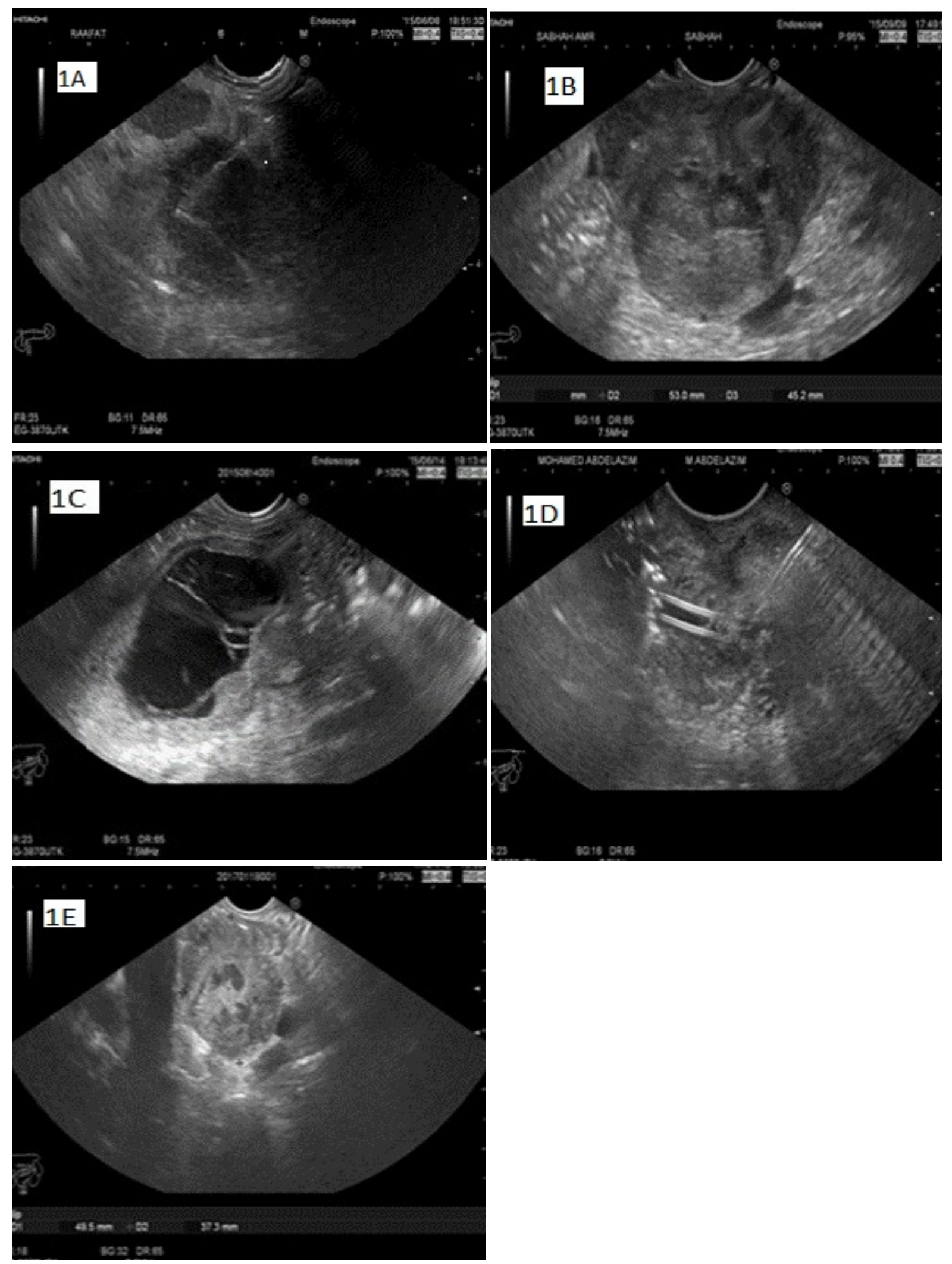

Figure 1. 1A) FNA of pancreatic cancer.1B) Large pancreatic head mass.1C) Pancreatic cyst. 1D) CBD stent and FNA inside a pancreatic mass.1E) Central necrosis inside a large pancreatic mass. 

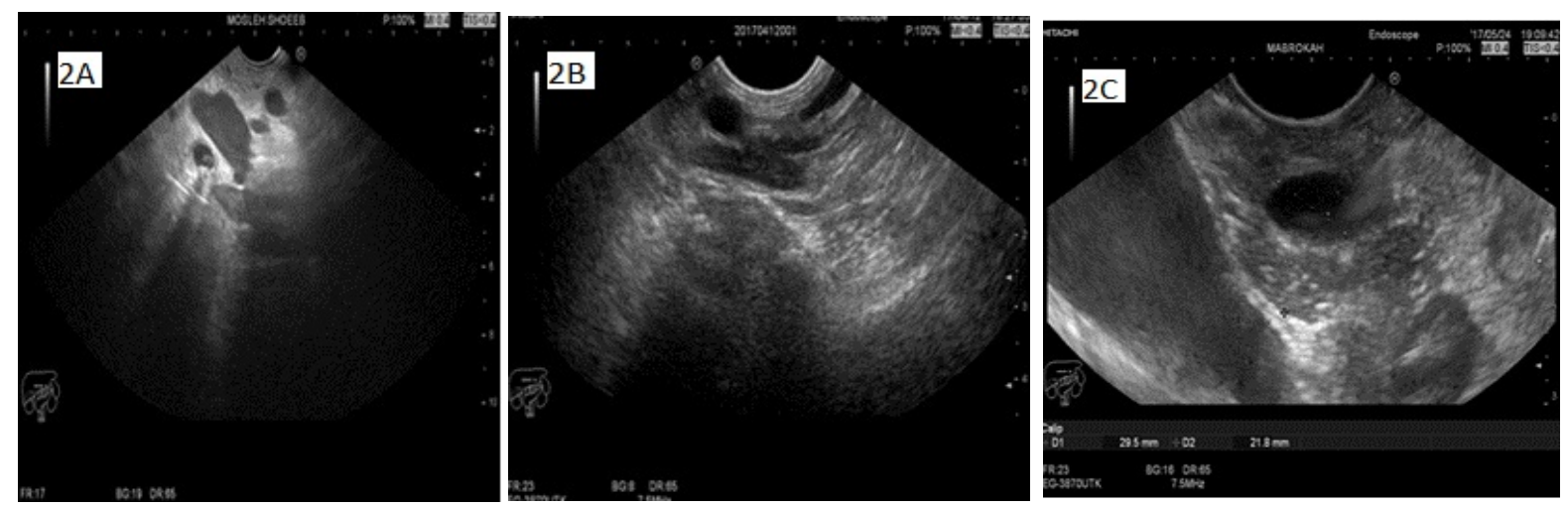

Figure 2:2A) CBD stones. 2B) CBD stent through an ampullary mass. 2C) Dilated CBD due to ampullary mass.
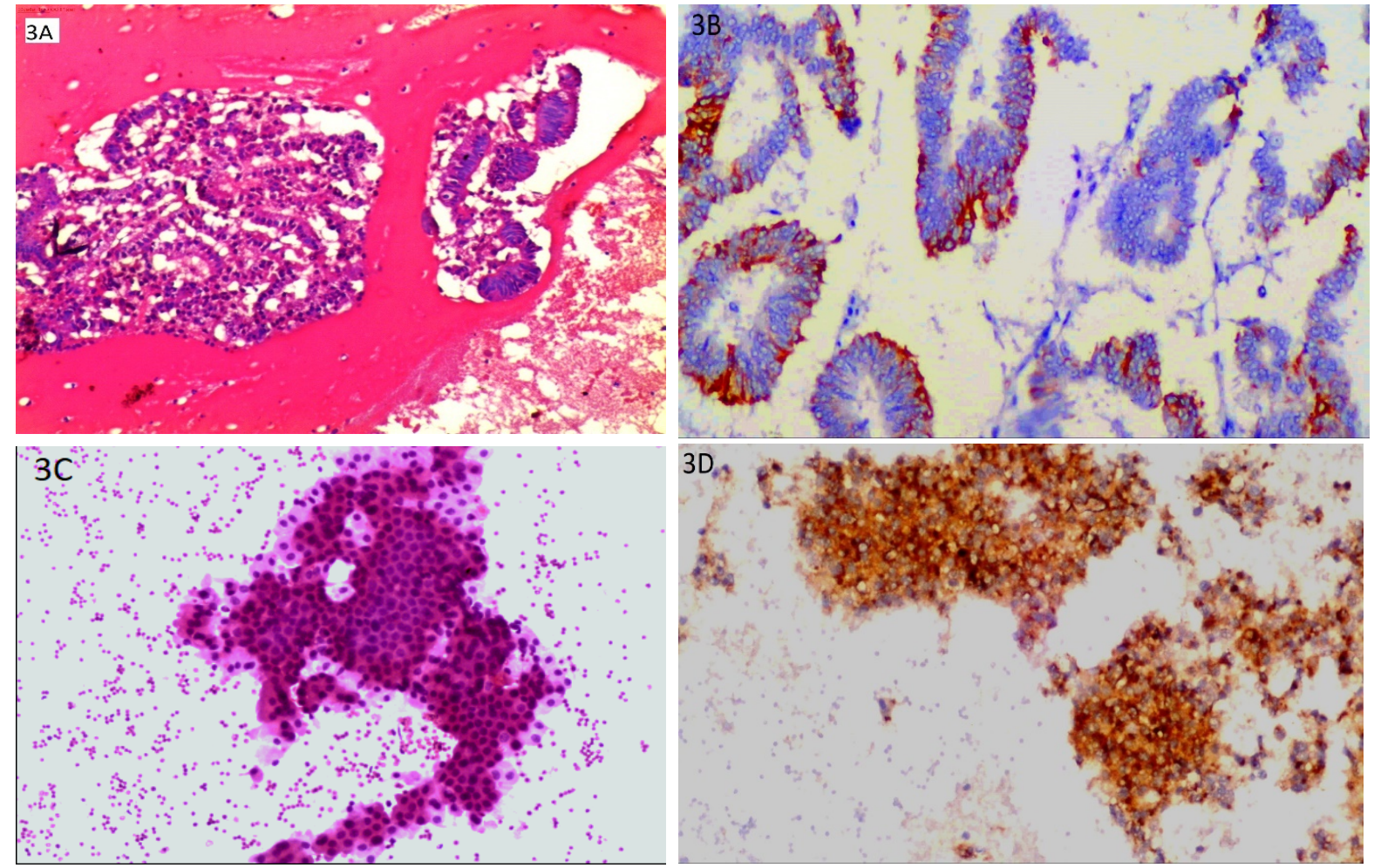

Figure 3. 3A) Cell block from pancreatic mass showing malignant glands suggesting adenocarcinoma (H\&E x400). 3B) Cell block showing positive cytokeratin 7 immunostaining in adenocarcinoma (streptavidin-biotin $\times 400$ ). 3C) FNAC from pancreatic mass showing groups of small monotonous cells suggesting pancreatic neuroendocrine tumor (H\&E X400). 3D) Cell block showing positive chromogranin-A immunostaining of pancreatic neuroendocrine tumor (streptavidin-biotin $\mathrm{x} 400$ ).
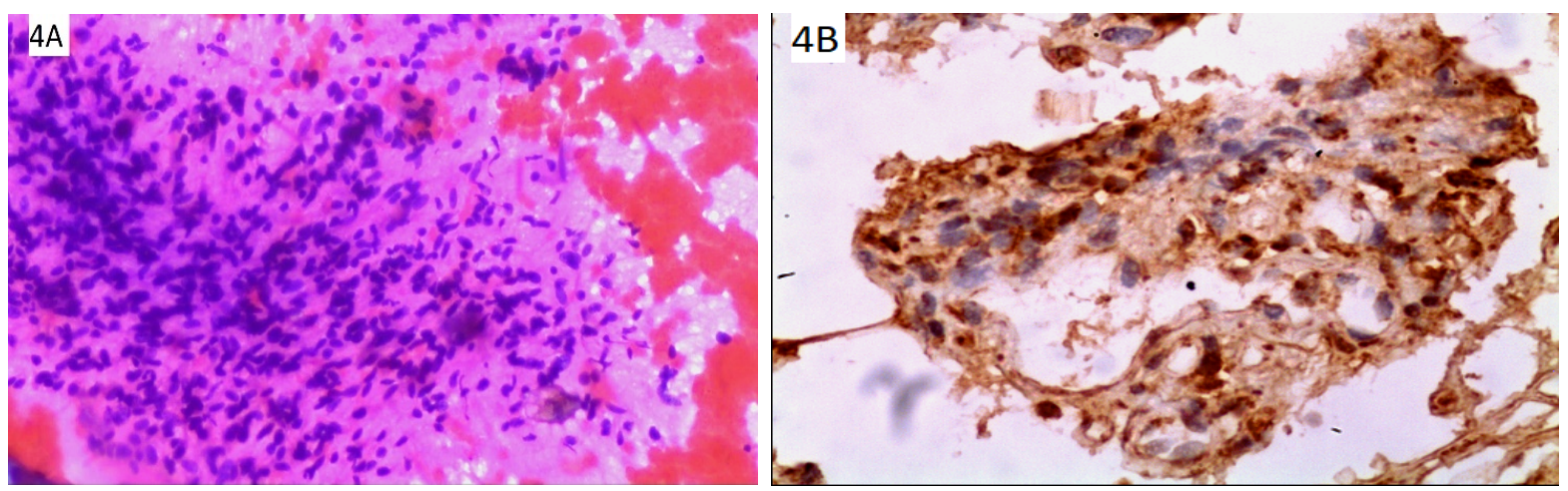

Figure 4. 4A), FNAC from gastric mass showing large atypical spindle cells suggesting GIST (H\&E x400).4B) Cell block showing positive C-kit immunostaining of neoplastic spindle cells (streptavidin-biotin $\times 400$ ). 

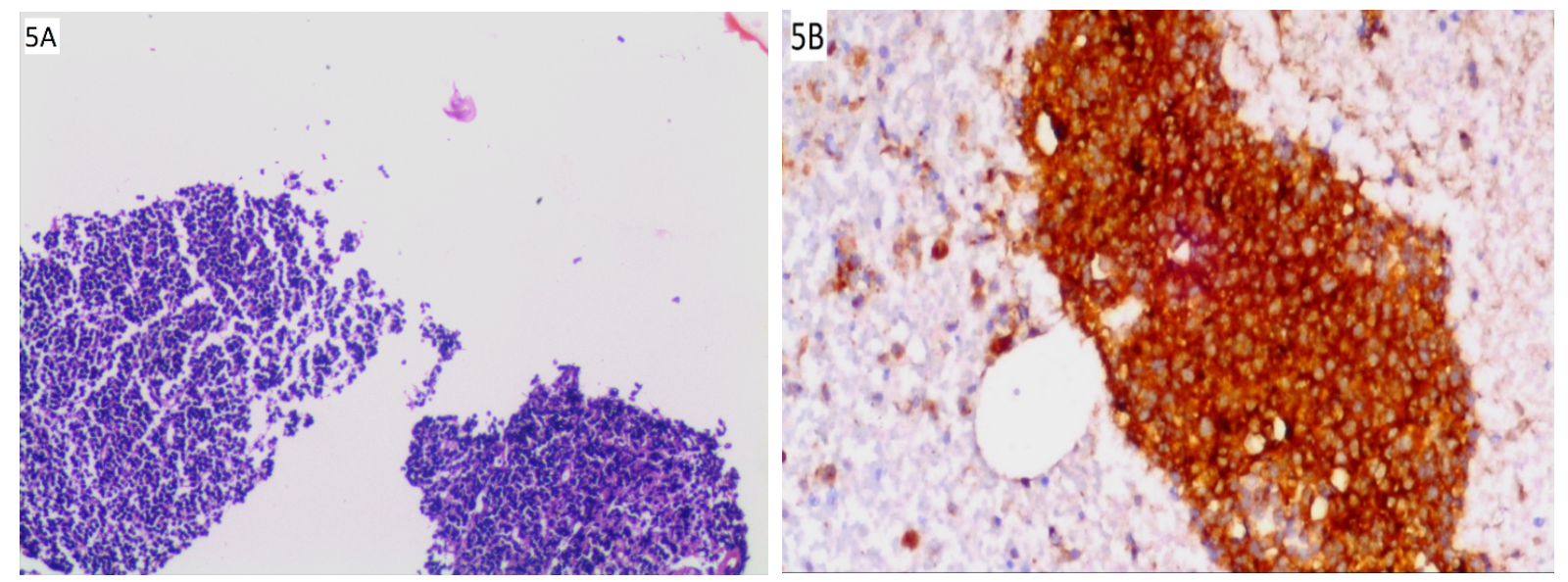

Figure 5. 5A) FNAC from mediastinal mass showing atypical rounded cells suggesting lymphoma (H\&E x100), 5B) Cell block showing positive LCA immunostaining of rounded neoplastic cells (streptavidin-biotin $\times 400$ ).

Gastric GIST and adenocarcinoma were the most frequent findings. (Hussain et al., 2009) reported that growth of stomach (11\%) was the third common indication for EUS referral in a study including 189 Pakistani patients and gastric malignant tumors were the main underlying etiology.

EUS is more suitable than CT in the establishment of the extent of wall invasion by gastric carcinoma. It can also reveal extragastric spread and local lymph node involvement that could be missed by CT. The accuracy of EUS for detecting the depth of invasion is $83-88 \%$ compared with $35 \%$ for CT. For detecting lymph node metastasis, EUS is 66$72 \%$ accurate compared with CT at $45 \%$ accuracy (Ho, 2003). EUS can differentiate carcinoma from lymphoma and is a most helpful technology for the assessment of possible GIST lesions that have a submucosal localization making them difficult to biopsy on conventional endoscopy. Recent studies have devised characteristics for discriminating features suggestive of benign or malignant behavior in GIST (Chak et al., 1997; Palazzo et al., 2000).

In our study, EUS guided coeliac axis block was performed for 6 cases to treat abdominal pain associated with pancreatic cancer in 5 cases and chronic pancreatitis in one case. According to a meta-analysis; the percentage of patients with pancreatic cancer pain for whom pain relief was attained by EUS-guided coeliac axis block was $80 \%$ (Puli et al., 2009). Moreover, the estimates for pain relief among chronic pancreatitis patients' consequent to EUS-guided coeliac axis block have been reported to be $51 \%$ to $59 \%$ (Puli et al., 2009; Kaufman et al., 2010).

Some side effects were recorded in a previous study, as $3 \%$ of cases had minor intraluminal bleeding after FNAC and $16.6 \%$ of cases had transient hypotension after EUS guided coeliac axis block. (Voss et al., 2000). Other studies revealed transient diarrhea and hypotension after EUS guided coeliac axis block in (4\%-15\%) and $(1 \%)$ of cases respectively (Sakamoto et al., 2011; Leblanc et al., 2013). The high percentage of transient hypotension after the coeliac axis block in our study may be attributed to the small number of cases.

\section{CONCLUSION}

The major indications for EUS were pancreatic, gastric and ampulla of Vater lesions, while the main outcomes were pancreatic adenocarcinoma, gastric GIST, adenocarcinoma, and ampullary adenocarcinoma. Therapeutic procedures were few in this study. No major complications were recorded.

\section{CONFLICT OF INTEREST}

Authors declare that they have no conflicts of interest.

\section{FUDING}

There is no financial support for this study.

\section{REFERENCES}

Amin MB, Edge S, Greene F, Byrd DR, Brookland RK, Washington MK, Gershenwald JE, Compton CC, Hess KR, Sullivan DC, Jessup JM, Brierley JD, 
Gaspar LE, Schilsky RL, Balch CM, Winchester DP, Asare EA, Madera M, Gress DM, Meyer LR, Eds. (2017). AJCC Cancer Staging Manual, Springer International Publishing.

Bhutani MS (2000). Interventional endoscopic ultrasonography: state of the art at the new millenium. Endoscopy, 32(1): 62-71.

Brugge WR (1998). Endoscopic ultrasonography: the current status. Gastroenterology, 115(6): 15771583.

Byrne MF, Jowell PS (2002). Gastrointestinal imaging: endoscopic ultrasound. Gastroenterology, 122(6): 1631-1648.

Chak A, Canto MI, Rosch T, Dittler HJ, Hawes RH, Tio TL, Lightdale CJ, Boyce HW, Scheiman J, Carpenter SL, Van Dam J, Kochman ML, Sivak MV, Jr. (1997). Endosonographic differentiation of benign and malignant stromal cell tumors. Gastrointest Endosc, 45(6): 468-473.

D'Souza SL, Holub JL, Pavic BT, Rodriguez SA (2016). Multicenter evaluation of the utilization of endoscopic ultrasound. Dig Endosc, 28(7): 738743.

Deprez PH (2013). EUS elastography: is it replacing or supplementing tissue acquisition? Gastrointest Endosc, 77(4): 590-592.

Dumonceau JM, Polkowski M, Larghi A, Vilmann P, Giovannini M, Frossard JL, Heresbach D, Pujol B, Fernandez-Esparrach G, Vazquez-Sequeiros E, Gines A, European Society of Gastrointestinal E (2011). Indications, results, and clinical impact of endoscopic ultrasound (EUS)-guided sampling in gastroenterology: European Society of Gastrointestinal Endoscopy (ESGE) Clinical Guideline. Endoscopy, 43(10): 897-912.

Hawes RH (2010). The evolution of endoscopic ultrasound: improved imaging, higher accuracy for fine needle aspiration and the reality of endoscopic ultrasound-guided interventions. Curr Opin Gastroenterol, 26(5): 436-444.

Hecht SM (2013). Comparison of three cell block techniques for detection of low frequency abnormal cells. Pathology and Laboratory Medicine International., 5 Pages 1-7.

Hewitt MJ, McPhail MJ, Possamai L, Dhar A, Vlavianos P, Monahan KJ (2012). EUS-guided FNA for diagnosis of solid pancreatic neoplasms: a meta-analysis. Gastrointest Endosc, 75(2): 319-331.

Ho SB (2003). Tumours of the stomach and small intestine. Current diagnosis and treatment in gastroenterology. F. SL. Bangkok, McGraw-Hill: 396.

Hussain T, Salamat A, Farooq MA, Hassan F, Hafeez $M$ (2009). Indications for endoscopic ultrasound and diagnosis on fine-needle aspiration and cytology. J Coll Physicians Surg Pak, 19(4): 223-227.

Kalade AV, Desmond PV, Chen RY (2006). Experience of endoscopic ultrasound in an Australian tertiary hospital. ANZ J Surg, 76(12): 10751080.

Kaufman M, Singh G, Das S, Concha-Parra R, Erber J, Micames C, Gress F (2010). Efficacy of endoscopic ultrasound-guided celiac plexus block and celiac plexus neurolysis for managing abdominal pain associated with chronic pancreatitis and pancreatic cancer. J Clin Gastroenterol, 44(2): 127-134.

Leblanc JK, Rawl S, Juan M, Johnson C, Kroenke K, McHenry L, Sherman S, McGreevy K, Al-Haddad M, Dewitt J (2013). Endoscopic UltrasoundGuided Celiac Plexus Neurolysis in Pancreatic Cancer: A Prospective Pilot Study of Safety Using $10 \mathrm{~mL}$ versus $20 \mathrm{~mL}$ Alcohol. Diagn Ther Endosc, 2013: 327036.

Palazzo L, Landi B, Cellier C, Cuillerier E, Roseau G, Barbier JP (2000). Endosonographic features predictive of benign and malignant gastrointestinal stromal cell tumours. Gut, 46(1): 88-92.

Puli SR, Reddy JB, Bechtold ML, Antillon MR, Brugge WR (2009). EUS-guided celiac plexus neurolysis for pain due to chronic pancreatitis or pancreatic cancer pain: a meta-analysis and systematic review. Dig Dis Sci, 54(11): 23302337.

Saftoiu A, Vilmann P (2013). Differential diagnosis of focal pancreatic masses by semiquantitative EUS elastography: between strain ratios and strain histograms. Gastrointest Endosc, 78(1): 188-189.

Sakamoto H, Kitano M, Komaki T, Imai H, Kamata K, Kudo M (2011). Endoscopic ultrasound-guided neurolysis in pancreatic cancer. Pancreatology, 11 Suppl 2: 52-58.

Skipper R, DeStephano DB (1989). A Rapid Stain for Campylobacter pylori in Gastrointestinal Tissue Sections Using Diff-Quik ${ }^{\circledR}$. Journal of Histotechnology, 12(4): 303-304.

Strohm WD, Phillip J, Hagenmuller F, Classen M (1980). Ultrasonic tomography by means of an ultrasonic fiberendoscope. Endoscopy, 12(5): 241-244.

Voss M, Hammel P, Molas G, Palazzo L, Dancour A, O'Toole D, Terris B, Degott C, Bernades P, Ruszniewski P (2000). Value of endoscopic ultrasound guided fine needle aspiration biopsy in the diagnosis of solid pancreatic masses. Gut, 46(2): 244-249. 


\section{Egyptian Association for Cancer Research (EACR)}

http://eacr.tanta.edu.eg/

EACR is an NGO society that was declared by the Ministry of Social Solidarity (Egypt) No. 1938 in 19/11/2014 based on the initiative of Prof. Mohamed Labib Salem, the current Chairman of EACR. EACR aims primarily to assist researchers, in particular young researchers in the field of cancer research through workshops, seminars and conferences. Its first international annual conference entitled "Anti-Cancer Drug Discovery" was successfully organized in April 2019 (http://acdd.tanta.edu.eg). Additionally, EACR aims to raise the awareness of the society about the importance of scientific research in the field of cancer research in prediction, early diagnosis and treatment of cancer. EACR is also keen to outreach the scientific community with periodicals and news on cancer research including peer-reviewed scientific journals for the publication of cutting-edge research. The official scientific journal of EACR is "International Journal of Cancer and biomedical Research (IJCBR: https://jcbr.journals.ekb.eg) was successfully issued in 2017 and has been sponsored by the Egyptian Knowledge Bank (EKB: www.ekb.eg).

\section{EACR Chairman,}

Prof. Mohamed Labib Salem, PhD

Professor of Immunology

Faculty of Science, Tanta Universiy, Egypt 
International Journal of Cancer and Biomedical Research (IJCBR), a publication of the Egyptian Association for Cancer Research (EACR), is a peer-reviewed online journal published quarterly. The journal allows free access (Open Access) to its contents and permits authors to self-archive a final accepted version of the articles on any OAl-compliant institutional / subject-based repository.

\section{Aim And Scope}

Aim: The main aim of IJCBR is to attract the best research in animal and human biology in health and diseases from across the spectrum of the biomedical sciences at the molecular, cellular, organ, and whole animal levels especially those that are related to cancer research, including causes, prediction, diagnosis, prognosis and therapy.

Scope: It is essential reading for all researchers interested in biochemistry, cancer, microbiology, nutrition, physiology, genetics, immunology, epidemiology, medical economics, human biology, bioinformatics, biotechnology, nanotechnology, and disease modeling.

\section{Publication Ethics}

Researchers should conduct their research from research proposal to publication in line with the best practices and codes of conduct of relevant professional bodies and/or national and international regulatory bodies. IJCBR accepts manuscripts prepared in accordance with the "Uniform Requirements for Submission of Manuscripts for Biomedical Journals adopted by the International Committee of Medical Journal Editors (ICMJE) and the Committee on Publication Ethics (COPE). Details of ICMJE and COPE are available at http://www.icmje.org/ and http://publicationethics.org/

\section{Peer Review Process}

After the IJCBR editor receives a manuscript, the first step is to confirm that the manuscript meets the journal's rules for content and format, including similarity check (plagiarism) which should be less than $25 \%$. If the manuscript meets the journal's rules, the editor then assign it to the double-blind peer review process. The IJCBR editor send the manuscript to at least two experts in the field for RIGOROUS scientific evaluation. The experts called peer reviewers - will then prepare a report that assesses the manuscript and return it to the editor through the IJCBR portal. Upon the first submission, this reviewing process takes about 4 to 6 weeks. After reading the peer reviewer's report, the editor will decide one of the following four options:

1. Reject the manuscript.

2. Accept the manuscript

3. Ask the authors to revise and resubmit the manuscript after responding to the peer reviewers' feedback.

4. Ask for peer-review from additional reviewers.

If the authors resubmit the manuscript, the IJCBR editor will ask the same peer-reviewers to look over the manuscript again to confirm that their concerns have been addressed. This is called re-review process. This second revision (if applicable) takes about another 4 to 6 weeks. At this point, the abstract of the article appears in press. The online publication (the PDF format) of the final version of the manuscript takes from 2 to 4 weeks. As such, the total publication cycle takes from 2 to 4 months. This cycle can be reduced to 4 to 6 weeks (fast track publication) for the manuscripts with outstanding findings.

The peer-review process used by IJCBR includes comments on errors in the study's methods or analysis that raise questions about the findings, or sections that need clearer explanations. The peer-review process also includes the importance and novelty of the manuscript and its interest to the journal's audience. The IJCBR uses double-blind review, which means that both the reviewers and authors identities are concealed from the reviewers, and vice versa, throughout the review process. To facilitate this, authors need to submit a Title Page containing the Authors details and Blinded Manuscript with no author details as 2 separate files. 


\section{Publisher}

The International Journal of Cancer and Biomedical Research (IJCBR) is an International and interdisciplinary journal of preclinical and clinical studies in the area of cancer and biomedical research. It is a peer-reviewed journal in English, published quarterly (in March, June, September, and December) by the Egyptian Association for Cancer Research (EACR) in both print and online formats (4 issues making a volume). Special issues or supplements may also be produced from time to time upon agreement with the Editorial Board.

\section{Scope}

The main aim of IJCBR is to attract the best research in animal and human biology in health and diseases from across the spectrum of the biomedical sciences at the molecular, cellular, organ, and whole animal levels especially those that are related to cancer research, including causes, prediction, diagnosis, prognosis and therapy.

\section{Publication Fees}

The journal does charge for submission, processing or publication of manuscripts (2000 LE for Egyptians or $\$ 300$ for non-Egyptians; EACR members receive 15\% discount on publication). Of them Peer-review fees (300 LE) should be paid on submission (non-refundable). For the fast track production of the accepted manuscript, another $500 \mathrm{LE}$ is paid.

General specifications for different types of article

- Submitted manuscripts should not have been published previously, except in a limited form (e.g. short communication to a symposium or as part of MSc or PhD theses) and should not be under consideration for publication by other journals.

- All co-authors should agree with the content of the manuscript. Authors must have obtained permission to use any copyrighted material in the manuscript before submission.

\section{IJCBR publishes different types of articles}

- Original Article (6000 words with $\mathbf{4}$ tables and $\mathbf{4}$ figures, maximum $\mathbf{8}$ display items): Articles with novel findings are the target of IJCBR. Articles presenting a detailed description of a new technique, comparison of existing methods, meta-analyses with comprehensive and in-depth discussion are considered. Papers in a numbered series are not accepted unless all are submitted at the same time.

- Short communications or case study (3000 words with 4 display items): Short communications present exceptionally exciting, novel or timely contents are considered. They will be peer-reviewed in the same way as research papers. The references are restricted to 15 .

- Reviews or systematic review (9000 words with $\mathbf{1 0}$ display items): They are invited by the Editorial Board or unsolicited. Review articles have to be contemporary and comprehensive and add information to the knowledge. Sharp critical analyses of novel data or concepts are encouraged. When relevant, a statistical analysis of data and a meta-analysis approach are recommended.

- Opinion papers, letter to the editor or comment to the editor (1500 words with $\mathbf{2}$ display items): They are submitted by invitation of the Editorial Board. They are short papers, which aim to inform scientists, industry, and the public and policymakers about cutting-edge issues in research or the impact of research. They reflect the opinion of their authors who bear full responsibility of the published paper. The references are restricted to 10 .

- Conference/Symposium papers: The journal will consider for publication the results of original work and critical reviews that are presented at conferences/symposia. Symposium organizers who wish to publish bundles of papers from a symposium/conference in IJCBR should first contact the Editor-inChief of the IJCBR (EACR@unv.tanta.edu.eg) for agreement. Supplementary material can be proposed and will be made available online. The responsibility for the preparation of a paper in a form suitable for publication lies with the author.

- Thesis: IJCBR can publish the summary and abstract of Master and PhD theses in a special issue. 
English: Good quality of written English is required. Spelling may be in British or American English but must be consistent throughout the paper. Care should be exercised in the use of biological terminology that is ill-defined or of local familiarity only. We recommend that authors have their manuscripts checked by an English language native speaker before submission.

Manuscript layout: Manuscripts should be prepared using a standard word processing program and presented in a clear readable format with easily identified sections and headings. The manuscript layout is based on the following directions.

- The main text contains Title, Abstract, Keywords, Introduction, Material and Methods, Results, Discussion, References, Tables, figures.

- The title needs to be concise and informative. Use bold, with an initial capital for the first word only and for words that ordinarily take capitals

- Short (running) title (max 80 characters including spacing).

- The article text should be typed with double-line spacing with wide margins $(2.5 \mathrm{~cm})$.

- The lines must be continuously numbered; the pages must also be numbered.

- Font Calibri 12 should be used for the text, and 12 for the tables, figure legends and references.

- The sections should typically be assembled in the following order:

- Title page contains title, authors' names, full affiliations, acknowledgements and the corresponding author's contacts and Short title.

Abstract (max 250 words, single paragraph): The abstract should be complete and understandable without citation, references, table or figure. Use structured abstract: Background, Aim, Materials \& Methods, Results and Conclusion. The context and the rationale of the study are presented succinctly to support the objectives. The experimental methods and main results are summarized but should not be overburdened by numerical values or probability values. The abstract ends with a short and clear conclusion.

Keywords: Up to five short and specific keywords should complement the title with respect to indicating the subject of the paper in alphabetic order.

Introduction: The introduction briefly outlines the context of the work, presents the current issues that the authors are addressing and the rationale to support the objectives, and clearly defines the objectives.

Material and methods: Material and methods should be described in sufficient details so that others can repeat the experiment. Reference to previously published work may be used to give methodological details, provided that said publications are readily accessible and in English. The code of ethics should be followed for all experiments use animals or human samples.

Statistical analysis of results: The statistical design and the models of statistical analysis must be described, as well as each of the statistical methods used. Sufficient statistical details must be given to allow replication of the statistical analysis. The experimental unit should be defined (e.g. individual or group of animals).

Results: Data are presented as tables and figures. Brief description of the results for each table and figure should be presented. Unpublished data can be mentioned when necessary.

Discussion: Should be separate from the Results section and should focus only on intra- and inter-data discussion (the data in the results section) as well as with the relative data in the literature. Don't repeat information already presented in the Introduction section. Start the first paragraph in the Discussion with a paragraph stating the rationale behind the study, the objectives and the main findings. End Discussion with a short conclusion.

Acknowledgements: In this section, the authors may acknowledge (briefly) their support staff.

Conflict of interest: All papers with a potential conflict of interest must include a description/explanation in a separate heading.

Funding details: The authors should state the source of findings of the study (with research funder and/or grant number). If no fund, the authors should state that the study is self-funded. 


\section{References}

Citation of references: In the text, references should be cited by the author(s) surname(s) and the year of publication (e.g. Salem, 2020). References with two authors should be cited with both surnames (e.g. Salem and Meshrif, 2021). References with three or more authors should be cited with the first author followed by et al. (in italics; e.g. Salem et al., 2021). Names of organizations used as authors (e.g. Food and Drug Administration) should be written out in full in the list of references and on the first mention in the text. Subsequent mentions may be abbreviated (e.g. FDA).

- List of references. Literature cited should be listed in alphabetical order by authors' names. It is the author's responsibility to ensure that all references are correct. All authors should be written and so the full journal name.

- References from journal articles are formatted in APA as this example: Al-Amoudi WM (2018). Toxic effects of Lambda-cyhalothrin on the rat thyroid. Involvement of oxidative stress and ameliorative effect of ginger extract. Toxicology Reports, 5: 728-736.

- References from books or official reports are formatted as this example. Kebreab E, Dijkstra ANM, Bannink A, Gerrits WJJ, \& France J (2006). Nutrient digestion and utilization in farm animals. CABI Publishing. Wallingford, UK.

- References from chapters or parts of books are formatted as this example. Nozière $P, \&$ Hoch $T$ (2006). Modelling fluxes of volatile fatty acids from rumen to portal blood. In: Nutrient digestion and utilization in farm animals (Kebreab E, Dijkstra ANM, Bannink A, Gerrits WJJ \& France J, eds.), pp. 40-47. CABI Publishing. Wallingford, UK.

Tables:

The data should be presented in tables or in graphs, not both.

- Each table should be placed on a separate page at the end of the main text.

- Tables are numbered consecutively using Arabic numbering. They are referred to as Table 1 , Table 2, etc., with capital ' $T$ ', no italics

- Each table has its explanatory caption. The caption is sufficient to permit the table to be understood without reference to the text.

- Abbreviations used in tables/figures have to be defined either as footnotes or in the caption.

Figures

- Package the figures in a single PowerPoint file. Each figure in a separate slide.

- Figure size should be readable in a width of approximately 8-175 $\mathrm{mm}$ (i.e. the maximum size of printing over two columns).

- Ensure that the font size is large enough to be readable at the final print size, use Calibri font to ensure that they are consistent throughout the figures.

- The figures should preferably be provided as TIFF or EPS files.

- The resolutions of figures must be at least $300 \mathrm{dpi}$.

- Preparation of images for a manuscript: For guidance, we refer to the Journal of Cell Biology's instructions to authors (http://jcb.rupress.org/site/misc/ifora.xhtml\#image_aquisition).

- If a cropped image is included in the main text of a paper (e.g. a few lanes of a gel), display the full original image, including the appropriate controls, the molecular size ladder and/or the scale as relevant, as a single figure in a Supplementary Material file to facilitate peer-review and for subsequent online publication.

- Supplementary material is submitted along with the main manuscript in a separate file and identified at uploading as "Supplementary File - for Online Publication Only" The title of the article is included at the top of the supplementary material.

Corresponding author's guidelines: Upon acceptance the corresponding author is required to send his/her recent formal photo to be attached to the front page of the article. 


\title{
International Journal of Cancer \& Biomedical Research
}

(IJCBR) Online ISSN 2682-2628

\author{
Editor-in-Chief \\ Mohamed Labib Salem, PhD \\ Tanta University, Egypt
}

\begin{tabular}{l} 
EACR Board \\
\hline Nehal Elmashad, MD \\
Tanta University, Egypt \\
Nabil Mohy Eldin, PhD \\
Kafrelsheikh University, Egypt \\
Doaa Al-Ghareeb, PhD \\
Alexandria University, Egypt \\
Abdel-Aziz Zidan, PhD \\
Damanhour University, Egypt
\end{tabular}

\begin{tabular}{l} 
Managing Editor \\
\hline Wesam Meshrif, PhD \\
Tanta University, Egypt \\
Sohaila Galal, PhD \\
Tanta University, Egypt \\
Production and Contact \\
\hline Hamdi Kandil \\
Tanta University, Egypt \\
Email: ljcbr100@gmail.com
\end{tabular}

\section{Advisory Board}

Alberto Montero, MD

Taussig Cancer Center, Cleveland,

USA

Yi Zhang, MD

Zhengzhou University, China

Mark Robunstein, Ph D

Medical University of South

Carolina, USA

Mohsen Farid, Ph D

Derby University, USA

Natarajan Muthusamy, Ph D

Ohio State University, USA

Hideki Kasuya, MD

Nagoya University, Japan

Sherif El-Khamisy, Ph D

Sheffield University, UK

Mohamed Ghanem, Ph D

Kafr Elshikh University, Egypt

Sayed Bakry, Ph D

Alazhar University, Egypt

Sameh Ali, Ph D

Nationa Liver Institute, Egypt

Gamal Badr, Ph D

Assuit University, Egypt

Nadia Hamdy, Pharm D

Ain Shams University, Egypt

\section{Editorial Board}

\section{Clinical studies}

Hesham Tawfik, MD

Tanta University, Egypt

Mohamed Attia, MD

Tanta University, Egypt

Mohamed Elshanshory, MD

Tanta University, Egypt

Essam Elshiekh, MD

Tanta Cancer Center, Egypt

Rasha Eraky, MD

Tanta University, Egypt

Shaima Abou-Kjatwa, MD

Tanta University, Egypt

Marcela Diaz, MD

Cleveland Clinic Foundation, USA

Mohamed Abou-El-Enein, MD

Charité Universitätsmedizin Berlin,

Germany
Alaa Eldin Almostafa, MD

McGill University, Canada

Olfat Gadallah, MD

Tanta University, Egypt

Nagla Sarhan, MD

Tanta University, Egypt

Naglaa Fathy, Pharm D

Zagazik University, Egypt

Mohamed Salama, MD

Mansoura University, Egypt

Mona Marie, MD

Alexandria University, Egypt

Preclinical studies

Mostafa El-Sheekh

Tanta University, Egypt

El-Refai Kenawy, Ph D

Tanta University, Egypt

Mohamed Noureldin, Ph D

Banaha University, Egypt

Yousry Albolkiny, Ph D

Tanta University, Egypt

Elsayed Salim, Ph D

Tanta University, Egypt

Shengdian Wang, Ph D

Chinese Academy of Sciences,

China

Sabry El Naggar, Ph D

Tnata Univesity, Egypr

Faris Alenzi, Ph D

Prince Sattam bin Abdulaziz

University, KSA

Ibrahim El-Sayed, Ph D

Menoufia University, Egypt

Tarek Aboul-Fadl, Ph D

Assiut University, Egypt

Rabab Khairat, Ph D

National Research Center,

Giza, Egypt

Wael Lotfy, Ph D

Alexandria University, Egypt

Ashraf Tabll, Ph D

National Research Center, Egypt

Nahla Shoukry, Ph D

Suez University, Egypt
Medhat Eldenary, Ph D

Tanta University, Egypt

Azza Hasan, Ph D

Menufia University, Egypt

Nanees Gamal Eldin, Ph D

Tanta University, Egypt

Mohamed Mansour, UK

Sabbah Hammoury, Ph D

Alexandria Ayadi Almostaqba

Oncology Hospital, Egypt

Nehal Aboulfotoh, Ph D

Zewail City for Science and

Technology, Cairo, Egypt

Amir Elkhami, Ph D

Galaxo, San Francisco, USA

Ahmed Alzohairy, Ph D

Zagazi University, Egypt

Wgady Khalil, Ph D

National Research Center, Egypt

Amr Amin, Ph D

United Arab Emirates

University, UAE

AbdelRahman Zekri, Ph D

National Cancer Institute, Egypt

Hussein Khamis, Ph D

Alexandria University, Egypt

Magdy Mahfouz, Ph D

Kafr Elsheikh University, Egypt

Ehab Elbedewey, Ph D

Tanta University, Egypt

Abeer Badr, Ph D

Cairo University, Egypt

Mamdooh Ghoneum, Ph D

Charles Drew University of

Medicine \& Science, USA

Haiam Abou Elela, Ph D

National Institute of Oceanography and Fisherie, Egypt

Maha EL-Demellawi, Ph D City for Scientific Research \&

Technology Applications, Egypt

Desouky Abd-El-Haleem, Ph D

City for Scientific Research \&

Technology Applications, Egypt 